\title{
Own HIVIAIDS Risk Perception and Associated Factors Among Mizan Tepi, University Students: Institution Based Cross-Sectional Study
}

\author{
Rameto Aman Nuri ${ }^{1, ~ *}$, Amene Abebe Kerbo ${ }^{2}$, Kemal Ahmed Kuti ${ }^{1}$ \\ ${ }^{1}$ Department of Public Health, Goba Referral Hospital, Madda Walabu University, Bale-Goba, Ethiopia \\ ${ }^{2}$ Department of Nursing, Goba Referral Hospital, Madda Walabu University, Bale-Goba, Ethiopia
}

Email address:

rametoaman@gmail.com (R. A. Nuri), ameneabe@gmail.com (A. A. Kerbo), kemal.ahmed5@gmail.com (K. A. Kuti)

\section{To cite this article:}

Rameto Aman Nuri, Amene Abebe Kerbo, Kemal Ahmed Kuti. Own HIV/AIDS Risk Perception and Associated Factors Among Mizan Tepi, University Students: Institution Based Cross-Sectional Study. American Journal of Health Research. Vol. 3, No. 6, 2015 , pp. 328-332.

doi: 10.11648/j.ajhr.20150306.12

\begin{abstract}
Introduction: HIV/AIDS is an extraordinary king of crisis; it is both an emergency and a long term development issue. Its impact goes beyond public health concerns as it undermines the social and economic structures particularly that of developing courtiers since it is mainly affecting economically active segment of the population. Objectives: Assessment of level of HIV risk perception and associated factors among Mizan-Tepi University students, southern, Ethiopia, 2011. Methods: Institutional based cross-sectional study supported with qualitative study design was conducted from April to May 2011. Data was collected from 627 randomly selected regular students using pretested structured questionnaire on self-administered basis. It was coded, entered, cleaned and analyzed using SPSS computer software package version 16. Summary statistics of socio demographic variables were presented using frequency tables and graphs. A logistic regressions analysis method was employed. Odds ratio with $95 \%$ confidence interval was used to assess the association of dependent and independent variables. P-value less than 5\% was used to declare significant association. Results: A total of 627 students were participated in the study making the response rate $97.4 \%$. Out of the total respondents 448 (71.5\%) were males. The mean age of the study population was 18.6 with standard deviation of 2.33 years. The prevalence of own HIV risk perception is $58.7 \%$. Age at first sexual intercourse, number of sexual partner, khat chewing found to be associated with own HIV risk perception. From varies socio-demographic characteristics of students, age group was important variable identified as predictor for own HIV risk perception by students. Conclusion: The overall prevalence of own HIV risk perception in this study is $58.7 \%$. Variables such as age at first sexual intercourse, number of sexual partner, khat chewing were identified to be strong predictors of own HIV risk perception.
\end{abstract}

Keywords: Risk, Perception, HIV/AIDS

\section{Introduction}

HIV/AIDS is an extraordinary king of crisis; it is both an emergency and along term development issue. Since the beginning of the pandemic, AIDS has been spreading at an alarming rate worldwide. Its impact goes beyond public health concerns as it undermines the social and economic structures particularly that of developing courtiers since it is affecting economically active segment of the population $[1,2]$.

Sub Saharan African countries, which constitute only $10 \%$ of the world population bear a huge global burden in what two out of three adults and nearly $90 \%$ of children infected with HIV live in this region, and more than three in four AIDS deaths occurred in the same region[3].
According to Ethiopia's 2007 single point estimates, the national adult (ages 15-49) HIV prevalence for 2008 was estimated to be $2.2 \%$ with an urban and rural HIV prevalence of $7.7 \%$ and $0.9 \%$ respectively [4]. Varies health related behavioral studies emphasizes the perception of being at risk of infection as being one of the necessary conditions for behavioral change. Moreover, the degree of the perceived risk seems to affect individual actual control in adopting preventive measures [5].

A study conducted on high-risk sexual behavior among youth in Tanzania revealed that $11.7 \%$ of the participants felt that they were at a high risk of getting HIV/AIDS and STDS, $25 \%$ felt that they had a very low risk, while $53.1 \%$ felt that they were not at risk at all. A study on young Zambian males 
showed that their risk perception of sexually transmitted infections (STIs) and HIV/AIDS was low due to misconceptions, folk beliefs and denial [6,7].

A similar study in Kolla Diba Town among high school students revealed that only $65(18.6 \%)$ felt that they could acquire HIV infections. According to the result of the study in Debre Birhan town, Participants' attitude towards perceiving themselves as susceptible to HIV infection was asked and the result indicated that $277(41.8 \%$ ) of them were replied that they have no chance of acquiring HIV $[11,12]$.

Based on the research conducted among youth population in Debre Birhan town, Knowledge of HIV prevention measures, Number of sexual partners, Condom utilization and Khat use were identified to be significant determinants of HIV/AIDS risk perception [12].

Youth particularly university students, even when aware of HIV risk, often do not consider this risk and stay with steady partners. In Ethiopia, according to the first National Behavioral Surveillance Survey, significant proportion of the population, particularly the youth were indicated to be at risk of HIV infection. Despite high level of knowledge about HIV/AIDS, most youth respondents (93.5\%) felt that they were not at risk or were at low risk for HIV infection. Varies health related behavioral strides emphasize the perception being at risk of infection as being one of the necessary conditions for behavioral change $[10,17]$.

Own HIV risk perception is a critical element in a comprehensive, effective and sustainable approach to HIV prevention and control [13].

Although some information on determinants of HIV/AIDS risk perception among different target groups is available, there is scarcity of information on students in this regard. There is no similar study done in the current study area as well. Thus, this study intended to assess determinants of HIV risk perception among Mizan-Tepi University students which provide basic information for the University responsible bodies and varies stake holders to design effective and sustainable intervention program for prevention and control of HIV/AIDS. Furthermore the information will enable policy makers and program planners to develop appropriate intervention program to halt the spread of HIV/AIDS.

\section{Methods}

\subsection{Study Design}

Institutional based cross-sectional study design supplemented with qualitative approach was conducted.

\subsection{Study Setting and Period}

The study was conducted in Mizan-Tepi University from April to May 2011. The University was established in 2007/08 G.C.which is located in SNNPR of Ethiopia around 565KM far from Addis Ababa. The University is organized in two campuses, namely Mizan and Tepi campus from which the name Mizan-Tepi University coined.

\subsection{Study Population}

The study populations were all regular Students of Mizan-Tepi University.

\subsection{Sample Size and Sampling Procedure}

Six hundred forty three (643) sample size was determined using single population proportion formula by taking prevalence of HIV risk perception of $58.2 \%$ which was taken from the study conducted among youth in Debre Birhan town. The total number of regular students in Mizan-Tepi University in the year of 2011 was 5230. Systematic random sampling technique was used by taking the interval of eight. For the qualitative part purposive sampling technique was employed to select students to be included in the focus group discussion.

\subsection{Data Collection Procedure}

The quantitative data was collected by structured and pre-tested self-administered Amharic version questionnaire adapted from similar previous studies and sample of questions that modified to this study setting. Eight diploma nurses and two supervisors (BSc. Nurse) were involved in the pre-testing of the questionnaire and collection of the actual data. Focus group discussion was conducted by using focus group discussion topic guide to collect qualitative data. Tape recorder was used to record the discussion. The investigator moderated the discussion; the note taker encoded each discussant according to their seat arrangement and wrote down their code without missing their sequence of speech.

\subsection{Data Quality Assurance}

The English version questionnaire was translated into Amharic language and back translated to English to check its consistency by respective language experts. The data collectors as well as supervisor were trained for two day on issue related to the overall data collection procedure. Ten percent of the questionnaire was pre-tested at Aman Health Science College and Aman technical and vocational training college to check acceptability and consistency and necessary correction was taken before the actual data collection. Further supervision by the principal investigator was done. The completeness of the questionnaire was checked frequently by supervisors and principal investigator. Tape recording during FGD was made at favorable place to facilitate the confidentiality and quality of data to be collected.

\subsection{Data Processing and Analysis}

The quantitative data were coded, entered, cleaned and analyzed using SPSS computer software package version 16 . Summary statistics of socio demographic variables were presented using frequency tables and graphs. Multiple logistic regression analysis was done to assess the association between the dependent variables and explanatory variables. Crude and adjusted Odds ratio with $95 \%$ confidence intervals was constructed. The qualitative study focused on the description of the status of HIV risk perception in the study population. Its 
analysis was done in parallel with the data collection. It includes the transcription and translation of the collected data. Data was systematically (or thematically) organized to address the research objective. Each emerging theme was supported by direct (verbatim) quotations.

\subsection{Ethical Consideration}

Ethical approval was obtained from institute of research and community support core process office of Mizan-Tepi University. Informed verbal and written consent was secured from each college principal and respective students for their participation after the purpose of the study was clearly explained for them. The right to refuse was respected and the information collected from the students was kept confidential as the collected information was stored in a file without the name of study participant and not revealed to anyone except the principal investigator and kept locked with key.

\section{Results}

A total of 627 students were participated in the study making the response rate $97.4 \%$. Out of the total respondents $448(71.5 \%)$ were males. The mean age of the study population was 18.6 with standard deviation of 2.33 years. As to marital status, Five hundred eighteen $(82.6 \%)$ of the participants were single. Students whose ethnic group belongs to Oromo constitute 274(43.7\%) (Table 1)

Table 1. Socio-demographic characteristics of Mizan-Tepi University students south west Ethiopia January, 2011.

\begin{tabular}{lll}
\hline Variable & Frequency & Relative Frequency \\
\hline Sex & & \\
Male & 448 & 71.5 \\
Female & 179 & 28.5 \\
Age category & & \\
$15-19$ & 131 & 209 \\
$>=20$ & 496 & 79.1 \\
Religion & & \\
Orthodox & 291 & 46.4 \\
Muslims & 161 & 25.7 \\
Protestant & 134 & 21.4 \\
Catholic & 14 & 2.2 \\
Others & 27 & 4.3 \\
Ethnicity & & \\
Oromo & 415 & 66.2 \\
Amhara & 142 & 22.6 \\
Tigre & 40 & 6.4 \\
Kembata & 20 & 3.2 \\
Others* & 10 & 1.6 \\
Marital status & & 82.6 \\
Single & 518 & 12.1 \\
Married & 76 & 3.2 \\
Divorced/separated & 20 & 2.1 \\
Widowed & 13 & \\
\hline
\end{tabular}

* Gurage, Wolayita, Kefa, Sidama, Dawuro

As it is presented on the bar chart below, students who started sexual intercourse at age below 19 years account nearly $127(30.2 \%)$ of the total population (figure 1 ).

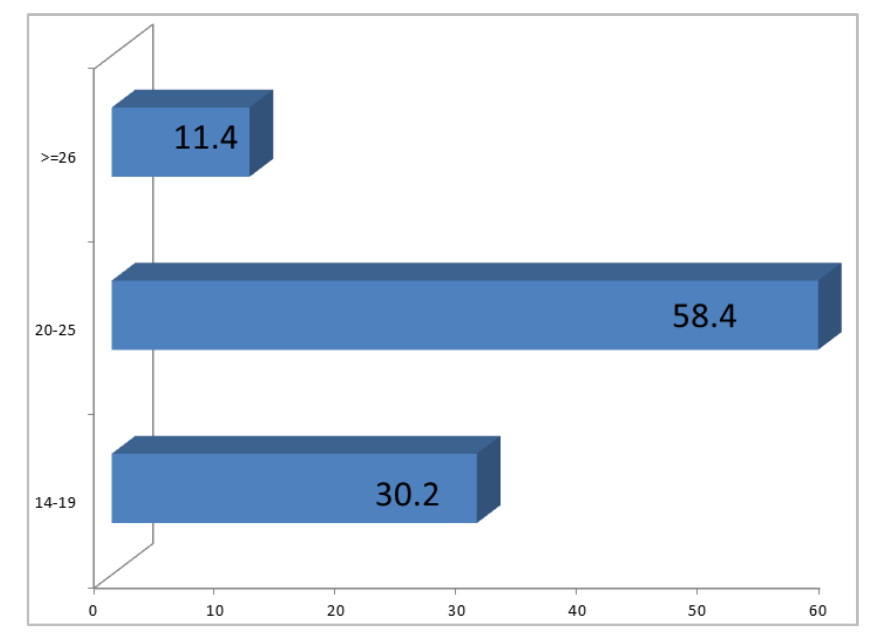

Figure 1. Age at first sexual debut among Mizan-Tepi university students Bench Maji and Sheka zone, SNNRS January, 2011.

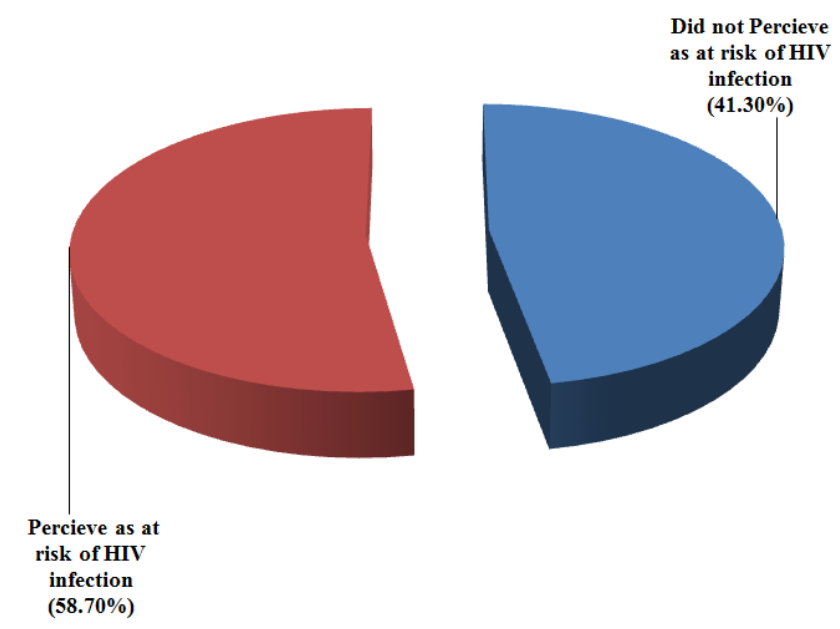

Figure 2. Level of own HIV risk perception among Mizan-Tepi university students Bench Maji and Sheka zone, SNNRS January, 2011.

According to this study significant proportion of students $62(14.8 \%$ ) encountered raped sexual intercourse (figure 3 ).

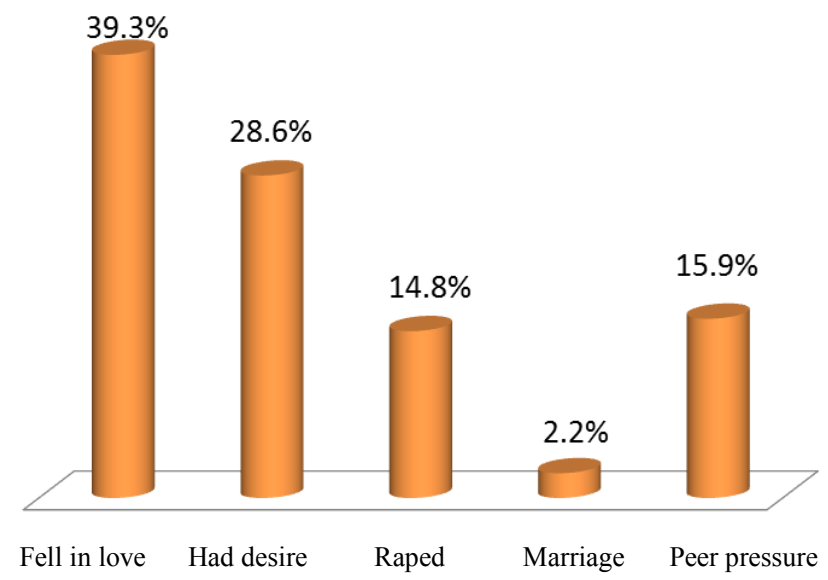

Figure 3. Reason to have sex among Mizan-Tepi university students, south west Ethiopia January, 2011. 
Table 2. Factors associated with own HIV risk perception among Mizan-Tepi university students Bench Maji and Sheka zone, SNNRS January, 2011.

\begin{tabular}{|c|c|c|c|c|}
\hline \multirow[t]{2}{*}{ Variables } & \multicolumn{2}{|c|}{$\begin{array}{l}\text { HIV risk } \\
\text { perception }\end{array}$} & \multicolumn{2}{|l|}{ OR $(95 \% \mathrm{CI})$} \\
\hline & Yes & No & $\operatorname{COR}(95 \% \mathrm{CI})$ & AOR (95\%CI) \\
\hline \multicolumn{5}{|c|}{ Having Sexual intercourse } \\
\hline Yes & 228 & 194 & $1.78(1.10,2.59)$ & $0.69(0.37,1.18)$ \\
\hline No & 140 & 68 & 1 & 1 \\
\hline \multicolumn{5}{|l|}{ Chat chewing } \\
\hline Yes & 350 & 242 & 1.00 & 1.00 \\
\hline No & 18 & 17 & $1.87(0.89,4.45)$ & $2.83(1.43,7.62)^{* *}$ \\
\hline \multicolumn{5}{|c|}{ Number of sexual partners } \\
\hline One & 60 & 60 & $1.34(0.92,1.96)$ & $1.84(1.01,3.36)^{* *}$ \\
\hline Two or more & 105 & 196 & 1 & 1 \\
\hline \multicolumn{5}{|c|}{ Age at first sexual intercourse } \\
\hline $14-19$ & 81 & 46 & 1 & 1 \\
\hline $20-25$ & 121 & 125 & $1.81(1.17,2.78)$ & $4.32(2.295,8.519)^{* *}$ \\
\hline$>=26$ & 25 & 23 & $1.55(0.80,3.00)$ & $5.11(1.85,16.10)^{* *}$ \\
\hline \multicolumn{5}{|c|}{ used condom correctly and consistently } \\
\hline Yes & 61 & 121 & $0.57(0.26,1.42)$ & $0.39(0.10,0.87)$ \\
\hline No & 102 & 137 & 1.00 & 1.00 \\
\hline \multicolumn{5}{|l|}{ Drink alcohol } \\
\hline Yes & 251 & 181 & $1.78(0.43,1.89)$ & $0.81(0.41,1.70)$ \\
\hline No & 117 & 78 & 1.00 & 1.00 \\
\hline \multicolumn{5}{|c|}{ Wanted to get tested HIV (VCT) } \\
\hline Yes & 324 & 232 & $1.84(0.43,1.48)$ & $0.71(0.21,1.79)$ \\
\hline No & 44 & 27 & 1.00 & 1.00 \\
\hline \multicolumn{5}{|l|}{ Age category } \\
\hline $15-19$ & 60 & 71 & 1 & 1 \\
\hline$>=20$ & 308 & 188 & $1.42(1.01,2.00)$ & $2.48(1.46,4.24)^{* *}$ \\
\hline
\end{tabular}

As to qualitative data participants mentioned that the main reason for having early sex were peer pressure, rape and abduction basically at rural part of our country, substance use like chat and alcohol and economic related problems as well. Having multiple sexual partners repeatedly mentioned by focus group discussants as a major factor for the spread of HIV/AIDS and other STIs. Some strongly argued that multiple sexual partners does not predispose to HIV, if safe sex is practiced. They mentioned that "absence of recreation place for the students in the campus was the main reason for students' sexuality as sex is one method of recreation for the students".

A 18 year old female student said "Some of the students perceive as there is no infection of HIV in the place like university where educated people are collectively present". According to participants, even though youth have high knowledge on HIV/AIDS they are poor in practicing HIV/AIDS prevention and control methods because of peer pressure, poverty, absence of recreation area, khat and drug abuse.

\section{Discussion}

Own HIV risk perception is known to be among the most powerful weapons in halting the spread of HIV/AIDS. The overall prevalence of Own HIV risk perception by students in this study is $58.7 \%$. It is higher when compared with research conducted on high-risk sexual behavior among youth in Tanzania that revealed $11.7 \%$ of the participants felt that they were at a high risk of getting HIV/AIDS and STDS, 25\% felt that they had a very low risk, while $53.1 \%$ felt that they were not at risk at all and a similar study conducted among students in secondary schools and colleges in Tanzania showed that only $25 \%$ of students felt that they themselves were personally at risk of acquiring HIV/AIDS [6, 8].

It is also higher than the result of study conducted on perception of the risks of sexual activities among out of school adolescents in south Gondar showed that participants' own HIV risk perception were $11(5.3 \%)$ of the rural and $13(11.2 \%)$ of the urban and the one conducted in Kolla Diba Town among high school students that revealed $65(18.6 \%)$ felt that they could acquire HIV infections [9, 11].The possible reason for this could be time gap between the studies, the difference in composition of study participant and recent accelerated expansion of HIV related information and services.

This study identified that students age category was known to be associated with own HIV risk perception. Being in age 20 and greater year is more than two times more likely to perceive as they are at risk of HIV compared with those in age group between 15-19 year $\quad(\mathrm{AOR}=$ $2.48,95 \% \mathrm{CI}=(1.46,4.24))$.

Age at first sexual intercourse was significantly associated with students own HIV risk perception. Students started sexual intercourse at age of twenty six and above were 5 times more likely to perceive as they are at risk of HIV compared with those started in age group between 15-19 year $(\mathrm{AOR}=5.11,95 \% \mathrm{CI}(1.85,16.10))$. This may be due to the fact that as age increase maturity will follow where students relatively get adequate information with regard to HIV/AIDS which possibly enable them to own perception.

This research also identified that number of sexual partner to be significant determinant of the own HIV risk perception of students. Students who have single sexual partner are nearly two times more likely perceived as they are at risk of HIV compared with those have multiple sexual partner $(\mathrm{AOR}=1.84,95 \% \mathrm{CI}((1.01,3.36))$. It is in line with study conducted in Uganda on the risk perception and condom use and research conducted among youth population in Debre Birhan town.

Chat chewing also another variable which was known to be significant determinant of own HIV risk perception. Students who did not chew khat are nearly 3 times more likely perceive as they are at risk of HIV compared with those chew khat ( $\mathrm{AOR}=2.83,95 \% \mathrm{CI}(1.43,7.62))$.

\section{Conclusion}

The overall prevalence of own HIV risk perception in this study is $58.7 \%$. From varies socio-demographic characteristics of students, age group was important variable identified as predictor for own HIV risk perception by students. Other variables such as age at first sexual intercourse, number of sexual partner, khat chewing were identified to be predictors of own HIV risk perception.

\section{Recommendation}

Mizan-Tepi University HIV prevention, control and 
mainstreaming office need to work on awareness creation on HIV/AIDS in collaboration with college of health science to equip students with comprehensive knowledge about HIV/AIDS. Mizan-Tepi university HIV prevention, control and mainstreaming office and FHAPCO need to work to increasing HIV risk perception. Mizan-Tepi university HIV prevention, control and mainstreaming office need to develop HIV work place policy so that the issue of HIV can be implemented well to halt the spread of the pandemic though increasing own HIV risk perception

\section{Authors' Contributions}

All authors contributed equally in all process which resulted with this outcome and preparing as well as reviewing the manuscript for publication.

\section{Acknowledgements}

First of all we would like to acknowledge Mizan-Tepi University, institute of research and community development and support for encouraging us and funding for the study. We would also like to extend our sincere thanks to health science staffs for their continuous support throughout the process. We wish to express our deep appreciation to all study participants for their cooperation and willingness in providing valuable information. Last but not least we wish to thank all data collectors, supervisors, and all our friends who supported us in all efforts to accomplish the task.

\section{References}

[1] MOH. National Guidelines for voluntary HIV counseling and testing in Ethiopia, Addis Ababa, Ethiopia.2000.

[2] UNAIDS Report on the global AIDS epidemic' 2008/9. Latest data update 9/8/2008 9:41:00 AM. Available at URL:http://WWW.unaids.org/en/knoledgecentre/HIVdata EPi

[3] UNAIDS/WHO. AIDS update, Geneva December 2007:1-20.
Available at URL: http://www.google. com.et $/$ search $? \mathrm{hl}=\mathrm{am} \&$ source $=\mathrm{hp} \& \mathrm{q}=2 \% 09$ UNAIDS $\% \ldots$

[4] Federal Ministry of health and /Federal HIV/AIDS Prevention and Control Office report 2007.

[5] Lavra B. Determinant of individual AIDS risk perception: knowledge, behavioral control and social influence. MPIDR working paper, July 2002.

[6] Ikamba L. and Ovedraogo B. High-risk sexual behavior: knowledge, attitudes and practice among youth at kichangan ward, Tanga, Tanzania. Action research ereports. 2003.

[7] Misconceptions, folk beliefs, denial hinder risk perception among young Zambian men: a research brief Sept 2003 no.3.

[8] Masulanya E, Moji K I Hariguchi, et.al. Knowledge, risk perception of AIDS and erported AIDS and reported sexual behavior among students in secondary schools and colleges in Tanzania. Health education research theory and practice 1999;14 (2):185-196.

[9] Kidane A. Sexuality, perception of risk of HI?V/STIs and condom use among high school adolescents in south Gondar, Amhara Region, (thesis ) Department of Community Health, Faculty of Medicine, Addis Ababa Unversity,2004.

[10] Lemma E. predictors of HI?V/AIDS related sexual behaviour of high-Schol adolescents based on the classical health behavior models, Jimma Town, Southwest Ethiopia. (thesis) Department of Community Health, Faculty of Medicine, Addis Ababa University, 2000.

[11] Ismail S, Bistuamlak $H$, and Alemu D. High-risk sexual behaviors for STD/HIV pregnancies and contraception among high school students in a rural town Northwestern Ethiopia. Ethiop. J. Health Dev. old reference please merge idea to recent then better to write recent; (1): 29-36.

[12] Zebideru Z. Assessment of HIV risk perception and condom use among youth in Debre Birhan town, Amhara region April 2005.

[13] Ahimbisibwe E, Odwee J. and Ayiga N. Risk perception and condom use in Uganda. African population studies vol. 18(1):68-80.

[14] HIV/AIDS Behavioral surveillance survey (BSS). Round one, Ethiopia, 2002. 